Article

\title{
Estimating the Relative Crystallinity of Biodegradable Polylactic Acid and Polyglycolide Polymer Composites by Machine Learning Methodologies
}

\author{
Jing Wang 1,*, Mohamed Arselene Ayari ${ }^{2,3, * \mathbb{D}}$, Amith Khandakar ${ }^{4} \mathbb{D}$, Muhammad E. H. Chowdhury ${ }^{4}$, \\ Sm Ashfaq Uz Zaman ${ }^{5}$, Tawsifur Rahman ${ }^{4}$ and Behzad Vaferi ${ }^{6}{ }^{(D)}$
}

1 College of Energy Engineering, Yulin University, Yulin 719000, China

2 Department of Civil and Architectural Engineering, College of Engineering, Qatar University, Doha 2713, Qatar

3 Technology Innovation and Engineering Education, College of Engineering, Qatar University, Doha 2713, Qatar

4 Electrical Engineering Department, College of Engineering, Qatar University, Doha 2713, Qatar; amitk@qu.edu.qa (A.K.); mchowdhury@qu.edu.qa (M.E.H.C.); tawsifur.rahman@qu.edu.qa (T.R.)

5 Department of Information Science \& Technology, Universiti Kebangsaan Malaysia, Bangi 43600, Malaysia; ashfaquzzaman2@gmail.com

6 Department of Chemical Engineering, Shiraz Branch, Islamic Azad University, Shiraz 7473171987, Iran; behzad.vaferi@gmail.com

* Correspondence: wangjingyulin@163.com (J.W.); arslana@qu.edu.qa (M.A.A.)

check for updates

Citation: Wang, J.; Ayari, M.A.;

Khandakar, A.; Chowdhury, M.E.H.; Uz Zaman, S.A.; Rahman, T.; Vaferi, B. Estimating the Relative Crystallinity of Biodegradable Polylactic Acid and Polyglycolide Polymer Composites by Machine Learning Methodologies. Polymers 2022, 14, 527. https:// doi.org/10.3390/polym14030527 Academic Editor: Claudia Barile Received: 27 November 2021 Accepted: 26 January 2022 Published: 28 January 2022

Publisher's Note: MDPI stays neutral with regard to jurisdictional claims in published maps and institutional affiliations.

Copyright: (C) 2022 by the authors. Licensee MDPI, Basel, Switzerland. This article is an open access article distributed under the terms and conditions of the Creative Commons Attribution (CC BY) license (https:// creativecommons.org/licenses/by/ $4.0 /)$.

\begin{abstract}
Biodegradable polymers have recently found significant applications in pharmaceutics processing and drug release/delivery. Composites based on poly (L-lactic acid) (PLLA) have been suggested to enhance the crystallization rate and relative crystallinity of pure PLLA polymers. Despite the large amount of experimental research that has taken place to date, the theoretical aspects of relative crystallinity have not been comprehensively investigated. Therefore, this research uses machine learning methods to estimate the relative crystallinity of biodegradable PLLA/PGA (polyglycolide) composites. Six different artificial intelligent classes were employed to estimate the relative crystallinity of PLLA/PGA polymer composites as a function of crystallization time, temperature, and PGA content. Cumulatively, 1510 machine learning topologies, including 200 multilayer perceptron neural networks, 200 cascade feedforward neural networks (CFFNN), 160 recurrent neural networks, 800 adaptive neuro-fuzzy inference systems, and 150 least-squares support vector regressions, were developed, and their prediction accuracy compared. The modeling results show that a single hidden layer CFFNN with 9 neurons is the most accurate method for estimating 431 experimentally measured datasets. This model predicts an experimental database with an average absolute percentage difference of $8.84 \%$, root mean squared errors of $4.67 \%$, and correlation coefficient $\left(R^{2}\right)$ of 0.999008 . The modeling results and relevancy studies show that relative crystallinity increases based on the PGA content and crystallization time. Furthermore, the effect of temperature on relative crystallinity is too complex to be easily explained.
\end{abstract}

Keywords: polylactic acid; polyglycolide; biodegradable composite; relative crystallinity; machine learning methods

\section{Introduction}

Biodegradable materials have recently grown in popularity due to their wide applicability in different practices, including for clinical purposes [1-3], drug delivery [4,5], and waste remediation [6-8]. Poly (L-lactic acid) (PLLA) is a low-toxic biodegradable polymer with good mechanical properties. Although PLLA has relatively satisfactory mechanical characteristics, its crystallization rate is slow. Hence, the fabrication of composites [9] based on PLLA with a better crystallization behavior has been suggested [10-12]. Chen 
et al. synthesized several completely biodegradable PLLA-based composites by dispersing polyglycolide (PGA) fibers in the PLLA body [12]. Several laboratory-scale investigations have been carried out to examine the effect of crystallization time, temperature, and PGA fiber dosage on the relative crystallinity of pure PLLA and PLLA/PGA composites [12].

Generally, the application domain of polymers is directly related to their physicochemical properties, including their tensile strength, elasticity, glass transition temperature, solubility, and crystallinity [12]. Crystallization is among the most complicated and longeststanding challenges related to polymer [13-15], composite [16], and zeolite [17] research and development. The relative crystallinity of polymers shows the degree of alignment of polymeric chains to one another [18]. Balani et al. claimed that polymer strength increases by increasing its crystallinity [19]. They also introduced the significant intermolecular bonding of the crystalline phase as the main factor responsible for their observation [19].

Differential scanning calorimetry, Raman spectroscopy, X-ray diffraction, nuclear magnetic resonance, infrared spectroscopy, small-angle $X$-ray scattering, and microscopy are the most common techniques for determining crystallinity and crystallization behavior [20]. Despite the diversity of experimental techniques, theoretical and modeling approaches are still rare in this topic. Molecular simulation is the most utilized method that provides some insight into polymer crystallization [21]. Therefore, our understanding of this complex subject is still incomplete and deserves further analysis.

The current study utilizes machine learning methods to accurately estimate PLLA/PGA composites' relative crystallinity. Six different artificially intelligent categories, including four artificial neural networks (ANN), two adaptive neuro-fuzzy inference systems, and least-squares support vector regression, were considered for this task. Systematic comparison analyses using four statistical indices confirmed that the cascade feedforward neural network provides the most reliable estimations for the relative crystallinity of PLLA/PGA composites. This model accurately predicts 431 experimentally measured datasets with an impressive average absolute percentage difference of $8.84 \%$, root mean squared errors of $4.67 \%$, and correlation coefficient $\left(\mathrm{R}^{2}\right)$ of 0.999008 . This model confirms that the relative crystallinity of pure PLLA and PLLA/PGA composites increases by increasing the crystallization time and reduces by reducing the crystallization temperature. Furthermore, PGA content in the PLLA-based composite has a weak increasing effect on relative crystallinity. To the best of our knowledge, there are no other studies in the literature which have conducted intelligent modeling related to the crystallinity processes of biodegradable PLLA/PGA composites.

\section{Materials and Experiments}

Chen et al. utilized the solvent method to fabricate several PLLA/PGA composites with 2-8 weight percent ( $w \mathrm{t} \%$ ) of the PGA fiber [12]. The differential scanning calorimetry (DSC) technique was employed to study the effect of PGA fibers on the isothermal crystallization of fabricated composites [12]. Table 1 shows the range of conducted experiments to measure relative crystallinity as a function of time, temperature, and PGA dosage in the considered polymers.

Table 1. Experiment data for the relative crystallinity of PLLA/PGA composites [12].

\begin{tabular}{ccccc}
\hline $\begin{array}{c}\text { Crystallization } \\
\text { Time (min) }\end{array}$ & $\begin{array}{c}\text { Crystallization } \\
\text { Temperature } \\
\left({ }^{\circ} \mathbf{C}\right)\end{array}$ & $\begin{array}{c}\text { PGA Dosage } \\
\mathbf{( w t} \%)\end{array}$ & $\begin{array}{c}\text { Relative } \\
\text { Crystallinity } \\
\mathbf{( \% )}\end{array}$ & $\begin{array}{c}\text { Numbers of } \\
\text { Measurements }\end{array}$ \\
\hline $0-50$ & $90-125$ & 0 & $0-100$ & 103 \\
\hline $0-40$ & $85-125$ & 2 & $0-100$ & 80 \\
\hline $0-35$ & $85-125$ & 4 & $0-100$ & 100 \\
\hline $0-35$ & $85-125$ & 6 & $0-100$ & 85 \\
\hline $0-25$ & $85-125$ & 8 & $0-100$ & 63 \\
\hline
\end{tabular}


It should be mentioned that pure PLLA is considered a composite with zero wt $\%$ of PGA fibers. This table shows that PLLA and all PLLA/PGA composites experience a maximum relative crystallinity of $100 \%$. On the other hand, the crystallization time of pure PLLA is almost twice that of a composite with $8 \mathrm{wt} \%$ of PGA fibers.

For a better presentation of the experimental study conducted by Chen et al. [12], the histogram of the considered variables is plotted in Figure 1. Histograms of crystallization time, temperature, PGA content of composites, and relative crystallinity are depicted in Figure 1A-D, respectively.
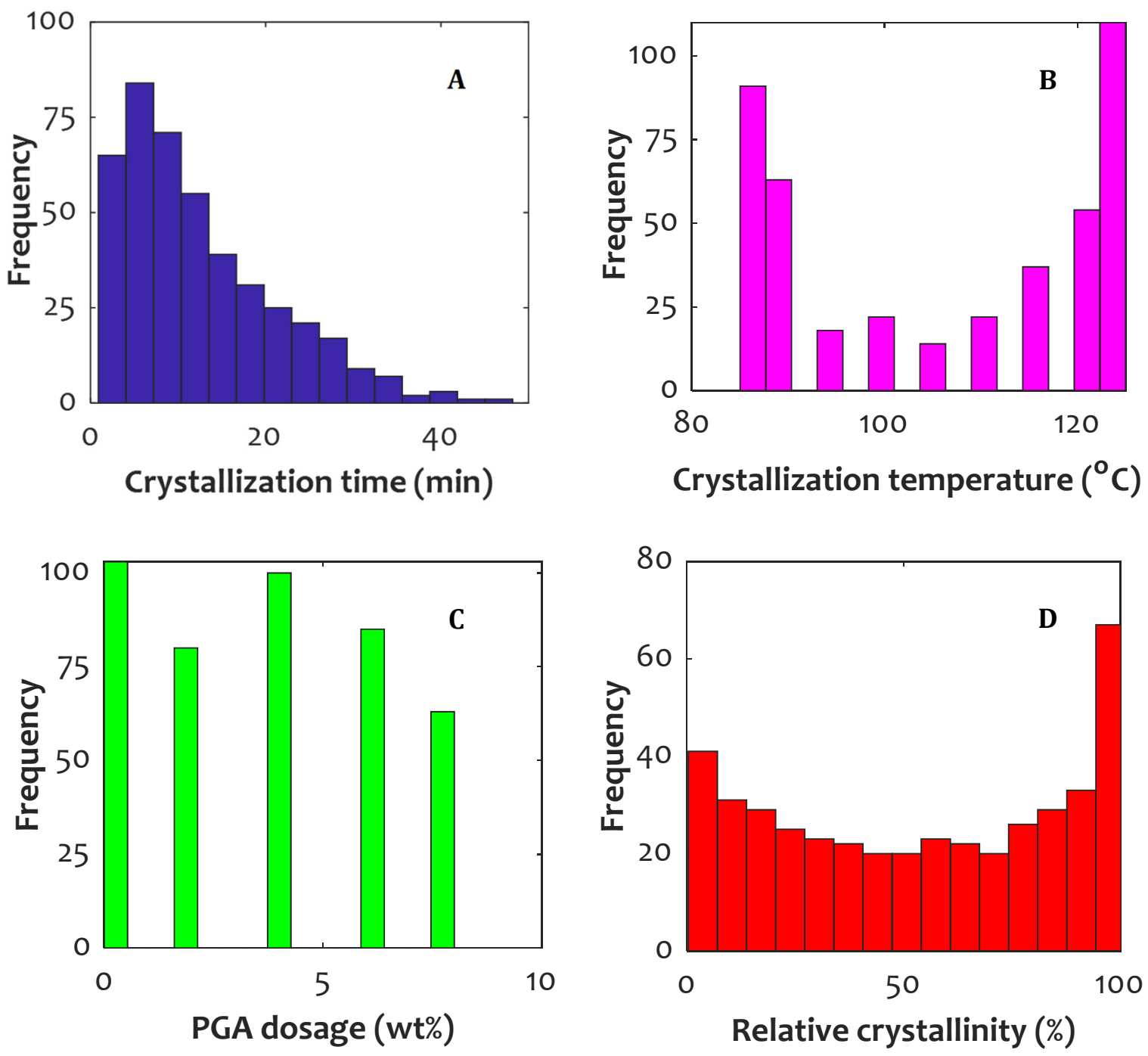

Figure 1. Histogram of experimental measurements for all of crystallization times (A), crystallization temperatures (B), PGA contents (C), and relative crystallinities (D).

\section{Methodology}

Machine learning is a trusted method to accurately estimate behaviors of different phenomena ranging from disease identification [22-26] and privacy-preserving healthcare $[27,28]$ to sustainable development [29]. As previously noted, this study constructs different machine learning methods and compares their accuracies to identify the most trustworthy topology for calculating the relative crystallinity of pure PLLA and PLLA/PGA composites. The multilayer perceptron neural network (MLPNN), recurrent neural network (RNN), cascade feedforward neural network (CFFNN), adaptive neuro-fuzzy inference system with subtractive clustering (ANFIS2) and c-means clustering (ANFIS3) membership functions, and least-squares support vector regression (LSSVR) have been employed in this regard. 


\subsection{Artificial Neural Networks}

Artificial neural networks were originally inspired by the operating practice of the neurological system of human beings [30]. Neurons are the smallest meaningful parts of neurological and artificial neural networks [31]. It is possible to place several neurons in some successive layers to create different topologies of the ANN. The MLPNN [32], CFFNN [33], RNN [34], radial basis function neural networks, and general regression neural networks are the most well-known ANN types in this regard. Our literature review confirmed that the first three aforementioned models often provide acceptable accuracy for regression-based problems. The mathematical and working backgrounds of MLPNN [35], CFFNN, and RNN [36] are well presented in the literature.

Cybenko theoretically confirmed that ANN models with only one hidden layer equipped with nonlinear, continuous, and differentiable activation functions are able to simulate even the most complicated phenomena [37]. The hyperbolic tangent and logistic activation functions satisfy the conditions proposed by Cybenko [37]. Therefore, it is only necessary to determine the number of neurons placed in the hidden layer.

\subsection{Adaptive Neuro-Fuzzy Inference Systems}

Adaptive neuro-fuzzy inference systems can be imagined as an organized combination of fuzzy logic and ANN methodologies [38]. This type of machine learning category is often built using five interconnected layers [38]. The membership function is the central part of the working procedure of the ANFIS-based model. Subtractive clustering and c-means clustering are the two most widely used membership functions in the ANFIS structure. It is necessary to determine the cluster radius for the former and the number of clusters for the latter [38]. Furthermore, an appropriate training algorithm also needs to be appropriately determined for developing the ANFIS-based model [38].

\subsection{Least-Squares Support Vector Regression}

Least-squares support vector regression is another machine learning method used in the current study [39]. This intelligent scenario uses the kernel function to transform the independent variable into a multidimensional space. Then, it is possible to linearly relate a target to its transformed independent variables. Suykens et al. comprehensively explained both the mathematical background and working procedure of the LSSVR [40]. An appropriate type of kernel function should be determined for the LSSVR-based estimator. Linear, polynomial, and Gaussian are possible kernel functions for incorporation in the LSSVR structure [40].

\section{Results and Discussion}

\subsection{Relevancy Analyses}

Both experimental [41] and modeling [42] studies have investigated the effects of the main influential variables on the considered dependent/target variable. Some statisticalbased methods are available for quantizing the direction and magnitude of relevancy between any pair of dependent-independent variables [43,44]. Spearman [45], Pearson [46], and Kendall [47] are three main instances in this field. These methods provide an index between -1 and +1 to show the direction and magnitude of dependency of a target to its influential features [48]. Table 2 explains the physical meaning of outcomes of these relevancy-monitoring methods. 
Table 2. Physical meaning of the Spearman, Pearson, and Kendall indices.

\begin{tabular}{ccc}
\hline Index Value & Direction of Relevancy & Magnitude of Relevancy \\
\hline-1 to $<0$ & Indirect & $\begin{array}{c}\text { Magnitude of indirect } \\
\text { relationship increases from } \\
\text { zero to }-1\end{array}$ \\
\hline 0 & No dependency & No dependency \\
\hline$<0$ to +1 & Direct & $\begin{array}{c}\text { Magnitude of direct } \\
\text { relationship increases from } \\
\text { zero to } 1\end{array}$ \\
\hline
\end{tabular}

In summary, the negative domain shows the indirect dependency of a dependent variable to an independent one and vice versa. On the other hand, -1 and +1 are associated with the strongest indirect and direct relationships, respectively. The magnitude of this relevancy decreases by converging the index to zero.

The results of applying the aforementioned relevancy scenarios on the collected databank for the relative crystallinity of the PLLA/PGA composites are graphically presented in Figure 2. Relative crystallinity directly relates to the crystallization time (strong) and PGA content of composites (weak). On the other hand, relative crystallinity has weak indirect relevancy with crystallization temperature.

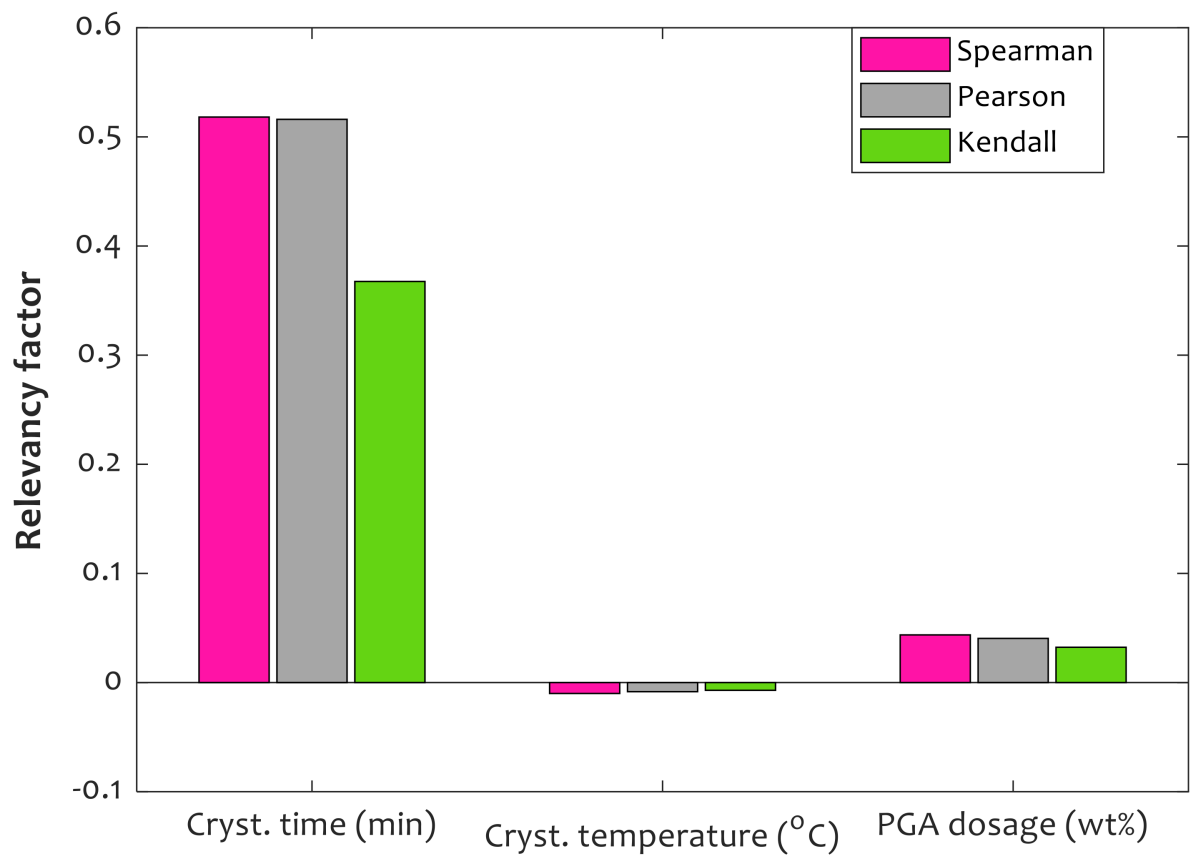

Figure 2. Interdependency of relative crystallinity on time, temperature, and PGA dosage.

\subsection{Developing Machine Learning Methods}

In order to efficiently use the considered machine learning techniques, their topologies need to be appropriately determined $[37,49,50]$. Since several rules of thumb prespecify some structural features of CFFNN, MLPNN, RNN, LSSVR, ANFIS2, and ANFIS3, it is only necessary to determine the rest of the features using a trial-and-error procedure. Table 3 divides the structural features of each technique into fixed and adjustable ones. 
Table 3. Summary of the trial-and-error process to find the best structural features of the machine learning methods.

\begin{tabular}{|c|c|c|c|}
\hline \multirow{2}{*}{ Machine Learning Method } & \multicolumn{2}{|c|}{ Structural Property } & \multirow{2}{*}{ Numbers of Model } \\
\hline & Fixed Property & Adjustable Property & \\
\hline MLPNN & $\begin{array}{l}\text { Number of hidden layers, i.e., two [37] } \\
\text { The activation function of the hidden } \\
\text { layer, i.e., hyperbolic tangent [37] } \\
\text { The activation function of the hidden } \\
\text { layer, i.e., logistic [37] } \\
\text { Training algorithm, i.e., } \\
\text { Levenberg-Marquardt [51] }\end{array}$ & Number of hidden neurons & 200 \\
\hline CFFNN & $\begin{array}{l}\text { Number of hidden layers, i.e., two [37] } \\
\text { The activation function of the hidden } \\
\text { layer, i.e., hyperbolic tangent [37] } \\
\text { The activation function of the hidden } \\
\text { layer, i.e., logistic [37] } \\
\text { Training algorithm, i.e., } \\
\text { Levenberg-Marquardt [51] }\end{array}$ & Number of hidden neurons & 200 \\
\hline RNN & $\begin{array}{l}\text { Number of hidden layers, i.e., two [37] } \\
\text { The activation function of the hidden } \\
\text { layer, i.e., hyperbolic tangent [37] } \\
\text { The activation function of the hidden } \\
\text { layer, i.e., logistic [37] } \\
\text { Training algorithm, i.e., scaled } \\
\text { conjugate gradient [52] }\end{array}$ & Number of hidden neurons & 160 \\
\hline LSSVR & $\begin{array}{l}\text { Training algorithm, i.e., least-squares } \\
\text { method [40] }\end{array}$ & Kernel function & 150 \\
\hline ANFIS2 & $\begin{array}{l}\text { Membership function, i.e., subtractive } \\
\text { clustering }[38,53]\end{array}$ & $\begin{array}{l}\text { Radius of cluster } \\
\text { Training algorithm }\end{array}$ & 400 \\
\hline ANFIS3 & $\begin{array}{l}\text { Membership function, i.e., c-means } \\
\text { clustering }[54,55]\end{array}$ & $\begin{array}{l}\text { Number of clusters } \\
\text { Training algorithm }\end{array}$ & 400 \\
\hline
\end{tabular}

\subsection{Selecting the Best Topology for Machine Learning Methods}

The experimental databank of the relative crystallinity of PLLA/PGA composites is randomly divided into training and testing collections. The former includes 366 datasets $(85 \%)$, and the latter constates 65 measurements $(15 \%)$. Five-fold cross-validation utilizes the training collection to determine the adjustable structural features and hyperparameters of the considered machine learning techniques. The testing collection is then engaged in evaluating the performance of the constructed paradigms. Four statisticalbased accuracy indices, including average absolute percentage difference $(A A P D \%)$, root mean squared errors (RMSE), correlation coefficient $\left(R^{2}\right)$, and relative absolute percentage error $(R A P E \%)$, help to find the most reliable topology for each machine learning technique. Equations (1)-(4) define mathematical formulations of $A A P D \%, R M S E, R^{2}$, and $R A P E \%$, respectively.

$$
\begin{aligned}
& A A P D \%=\frac{100}{N} \sum_{j=1}^{N} \frac{\left|R C^{\exp }-R C^{c a l}\right|_{j}}{R C_{j}^{\exp }} \\
& R M S E=\sqrt{\frac{1}{N} \sum_{j=1}^{N}\left(R C^{\exp }-R C^{c a l}\right)_{j}^{2}}
\end{aligned}
$$




$$
\begin{gathered}
R^{2}=1-\frac{\sum_{j=1}^{N}\left(R C^{\exp }-R C^{c a l}\right)_{j}{ }^{2}}{\sum_{j=1}^{N}\left(R C^{\exp }-\overline{R C^{\exp }}\right)_{j}{ }^{2}} \\
R A P E \%=\frac{100 \times \sum_{j=1}^{N}\left|R C^{\exp }-R C^{c a l}\right|_{j}}{\sum_{j=1}^{N} \mid R C^{\exp }-\overline{\left.R C^{\exp }\right|_{j}}}
\end{gathered}
$$

All above equations need experimental measurements $\left(R C^{\mathrm{exp}}\right)$, calculated values $\left(R C^{c a l}\right)$ of the relative crystallinity $(R C)$, and numbers of training or testing datasets $(N)$ to be calculated.

The performance of the constructed models was compared using these statistical criteria to find those adjustable features that present the highest accuracy in the training and testing stages. Table 4 introduces the best adjustable features for each class of the machine learning method. This table also reports the accuracy of the selected models for the training and testing collections as well as their combination, i.e., overall database. The reported accuracies in Table 4 show that the adaptive neuro-fuzzy inference system with the c-means clustering membership function (i.e., ANFIS3) is the model that predicts both training and testing collections with the highest uncertainty. This model estimates 431 experimental measurements of the relative crystallinity of PLLA/PGA composites with $A A P D=24.78 \%, R A P E=14.53 \%, R M S E=6.54$, and $R^{2}=0.980306$.

Table 4. The most appropriate features for the machine learning methods determined through the

\begin{tabular}{|c|c|c|c|c|c|c|}
\hline Model & The Most Appropriate Characteristics & Collection & AAPD $\%$ & RAPE \% & RMSE & $\mathbf{R}^{2}$ \\
\hline \multirow{3}{*}{ MLPNN } & Nine hidden neurons & Training & 11.13 & 7.38 & 4.95 & 0.988679 \\
\hline & Hyperbolic tangent and logistic & Testing & 6.25 & 5.37 & 2.38 & 0.997467 \\
\hline & Levenberg optimization algorithm & Overall & 10.39 & 7.07 & 4.65 & 0.990062 \\
\hline \multirow{3}{*}{ CFFNN } & Nine hidden neurons & Training & 8.74 & 6.68 & 4.54 & 0.990058 \\
\hline & Hyperbolic tangent and logistic & Testing & 9.42 & 7.28 & 5.32 & 0.990337 \\
\hline & Levenberg optimization algorithm & Overall & 8.84 & 6.76 & 4.67 & 0.990082 \\
\hline \multirow{3}{*}{ RNN } & Seven hidden neurons & Training & 10.92 & 9.81 & 4.00 & 0.992677 \\
\hline & Hyperbolic tangent and logistic & Testing & 11.07 & 13.76 & 9.14 & 0.966081 \\
\hline & Scaled conjugate gradient algorithm & Overall & 10.94 & 10.44 & 5.12 & 0.988174 \\
\hline \multirow{3}{*}{ LSSVR } & \multirow{3}{*}{ Gaussian kernel function } & Training & 13.03 & 8.14 & 5.22 & 0.987382 \\
\hline & & Testing & 14.13 & 8.78 & 4.33 & 0.992005 \\
\hline & & Overall & 13.20 & 8.24 & 5.09 & 0.988064 \\
\hline \multirow{3}{*}{ ANFIS2 } & \multirow{3}{*}{$\begin{array}{l}\text { Hybrid optimization algorithm } \\
\quad \text { Cluster radius }=0.5\end{array}$} & Training & 8.54 & 5.27 & 4.41 & 0.991163 \\
\hline & & Testing & 16.28 & 8.79 & 5.36 & 0.985432 \\
\hline & & Overall & 9.71 & 5.74 & 4.57 & 0.990414 \\
\hline \multirow{3}{*}{ ANFIS3 } & \multirow{3}{*}{$\begin{array}{l}\text { Hybrid optimization algorithm } \\
\text { Nine clusters }\end{array}$} & Training & 25.81 & 13.87 & 6.29 & 0.981923 \\
\hline & & Testing & 19.01 & 18.39 & 7.78 & 0.971648 \\
\hline & & Overall & 24.78 & 14.53 & 6.54 & 0.980306 \\
\hline
\end{tabular}
trial-and-error process.

Figure 3 reports the outcome of the ranking analysis performed to order the selected models in Table 4 based on their average prediction accuracy over the training, testing, and overall collections. Indeed, the average efficiency of each model has been measured using 
their AAPD \%, RAPE\%, RMSE, and $\mathrm{R}^{2}$ values. This figure shows that ANFIS2 and MLPNN have the best performance in the training and testing stage, respectively. Since MLPNN badly estimates the training collection and ANFIS2 prediction for the testing stage is not very good, neither of them should be selected as the most trusted model. On the other hand, the CFFNN model with the second prediction ranking for the training, testing, and overall collections is a better selection for estimating the relative crystallinity of pure PLLA and PLLA/PGA composites.

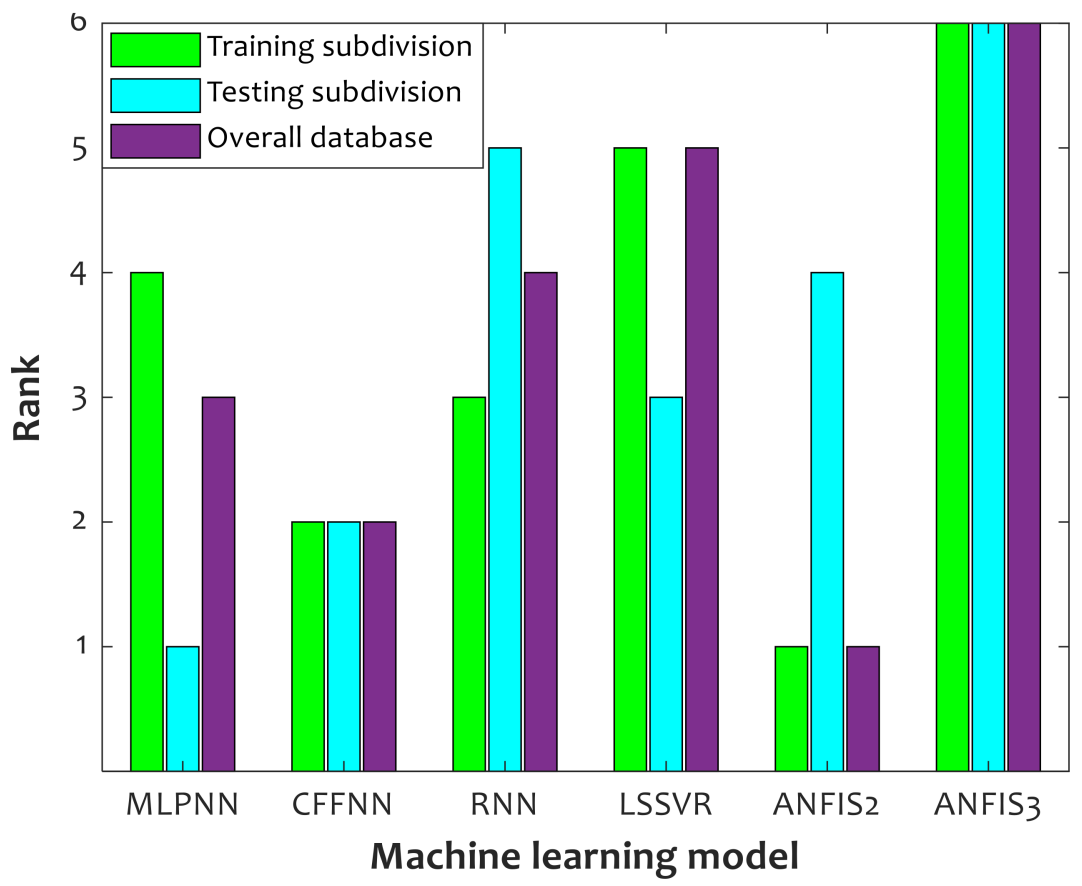

Figure 3. Ranking of machine learning methods during model development, model validation, and their combination.

\subsection{Investigating the Effect of Activation Function on CFFNN Performances}

Cybenko stated that a continuous, nonlinear, and differentiable activation function such as hyperbolic tangent and logistic is better to utilize in the structure of artificial neural networks [37]. However, it is not clear what combination of these activation functions shows the best predictive performance. Table 5 reports the prediction accuracy of CFFNN with different combinations of the hyperbolic tangent and logistic activation functions. The first row of this table shows the previously achieved results (see Table 4) by the hyperbolic tangent and logistic activation functions in the hidden and output layers, respectively. The second row of Table 5 confirms that it is possible to improve the prediction accuracy of the CFFNN model.

Table 5. Investigating the effect of activation functions on the predictive performances of the CFFNN method.

\begin{tabular}{ccccc}
\hline Hidden Layer & Output Layer & Training & Testing & Overall \\
\hline Hyperbolic tangent & Logistic & 8.74 & 9.42 & 8.84 \\
\hline Logistic & Logistic & 7.97 & 8.61 & 8.06 \\
\hline Logistic & Hyperbolic tangent & 8.33 & 6.80 & 8.10 \\
\hline Hyperbolic tangent & Hyperbolic tangent & 9.35 & 5.53 & 8.78 \\
\hline
\end{tabular}

In summary, a single hidden layer CFFNN with nine hidden neurons equipped with the logistic activation functions in its layers is the most accurate model for predicting the 
relative crystallinity of pure PLLA and PLLA/PGA composites. Therefore, all the following analyses were directed using this intelligent method.

Figure 4 presents the iterative procedure that the Levenberg-Marquardt passes to adjust hyperparameters of the CFFNN model. After 100 iterations, the mean squared errors (MSE) between experimental and prediction values of the relative crystallinity converge to the predefined desired value, i.e., $M S E=0.75 \times 10^{-3}$. The $M S E$ value can be calculated using Equation (5).

$$
M S E=\frac{1}{N} \sum_{j=1}^{N}\left(R C^{\exp }-R C^{c a l}\right)_{j}^{2}
$$

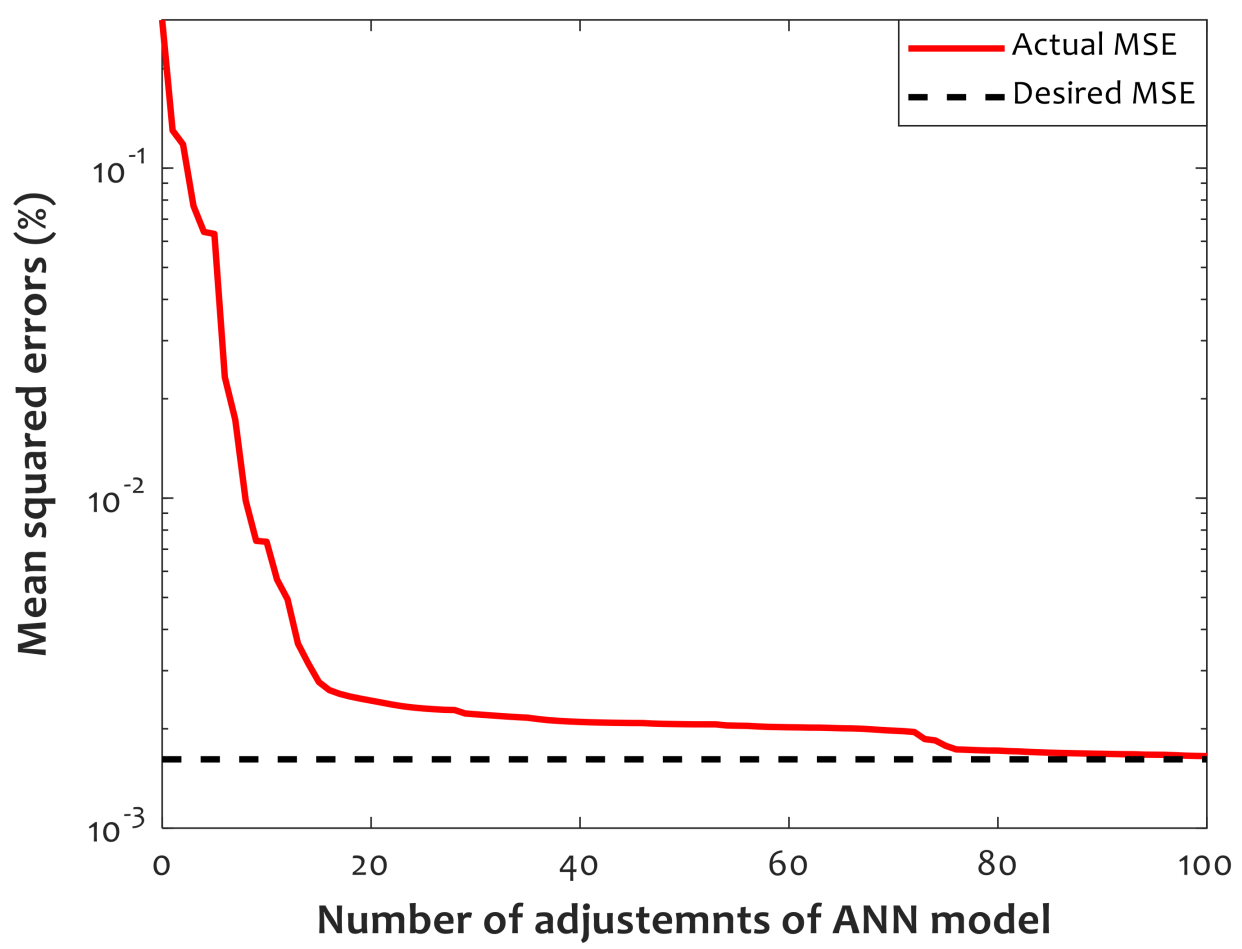

Figure 4. Results of the iterative procedure conducted using the Levenberg-Marquardt to train the CFFNN method.

\subsection{Analyzing the Performance of the CFFNN Model}

A cross-plot of the estimated relative crystallinities by the proposed CFFNN with respect to their corresponding experimentally measured information is shown in Figure 5. It can be observed that almost all CFFNN predictions have been successfully mapped on their associated experimentally measured data points. Moreover, the previously achieved results in Table 4 state that the regression coefficients for the training, testing, and overall collections are $0.990058,0.990337$, and 0.990082 , respectively.

Figure 6 depicts the residual error (Equation (6)) histogram between the CFFNN predictions and actual values of relative crystallinity of pure PLLA and PLLA/PGA composites.

$$
\text { Residual error }=\left(R C^{\exp }-R C^{c a l}\right)
$$




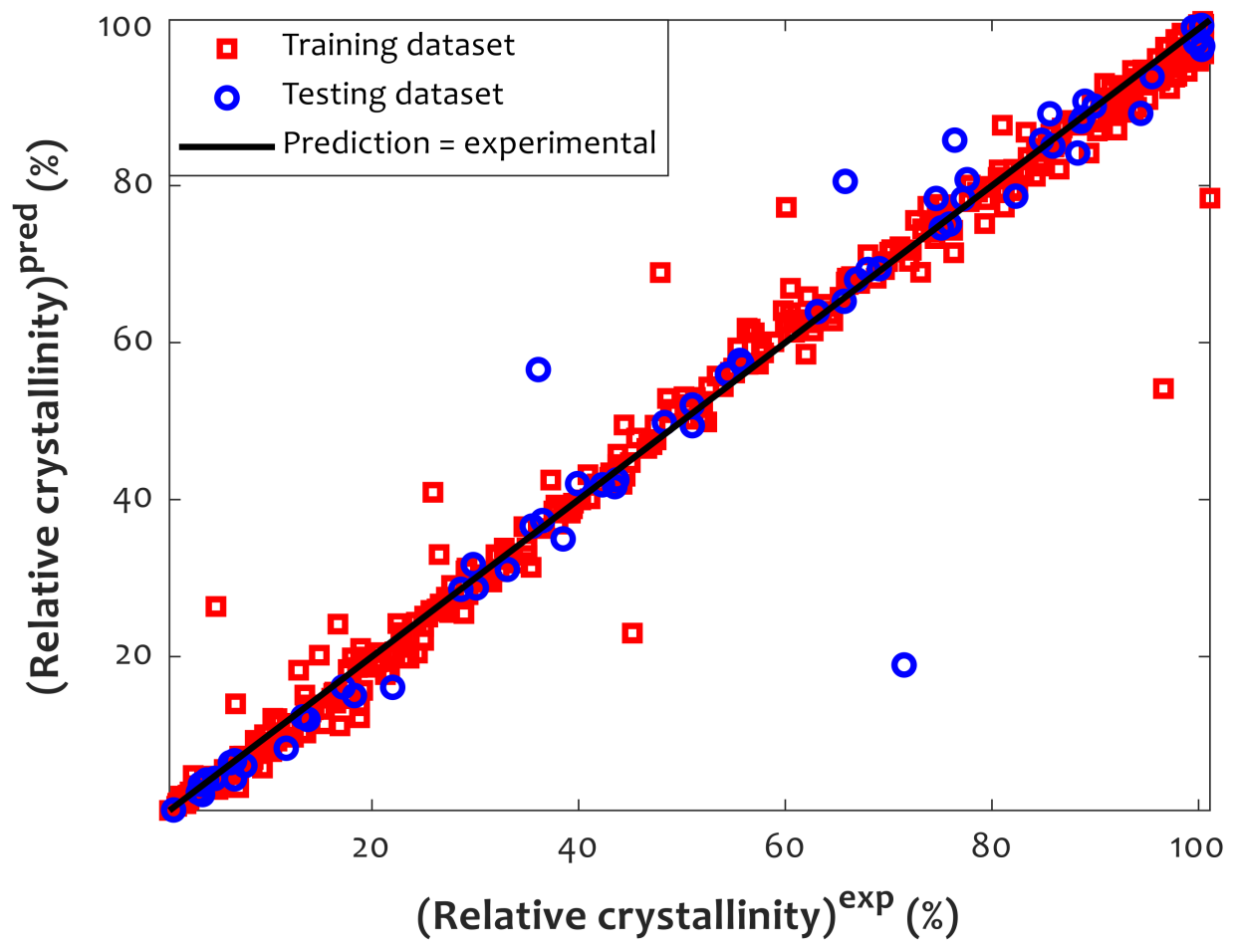

Figure 5. Predicted versus actual measured values of relative crystallinity.

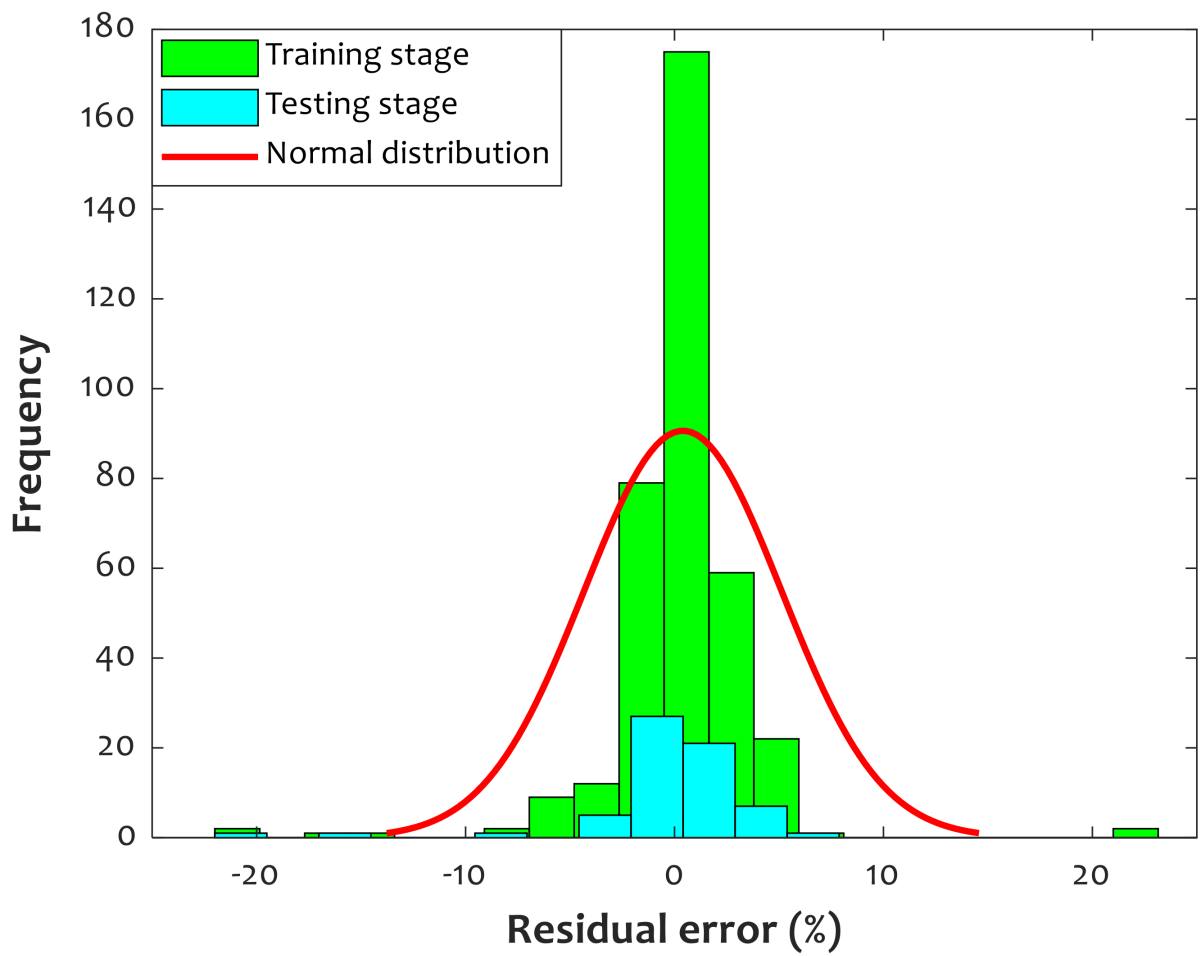

Figure 6. Histogram presentation of deviation between predicted and actual values of relative crystallinity (average error $=0.398 \%$, standard deviation $=4.72 \%$ ).

This figure confirms that the maximum residual error of $+10 \%$ and minimum value of $-10 \%$ are provided by the fabricated CFFNN model. It can also be observed that $\sim 175$ training samples and $\sim 23$ testing samples were simulated with zero residual error. The fitted red curve confirms that the observed results obey normal distribution. 
Kernel density estimation [56] is employed to plot a distribution of the CFFNN predictions and actual values of the relative crystallinity data collections (see Figure 7). Although the data distribution is very close to normal distribution, two normal distributions can be simply detected. Furthermore, the distributions of CFFNN predictions and actual values are almost identical. The predicted and actual distributions are slightly different between the magnitudes of 15 and 85 . Hence, Figure 7 confirms the robustness of the proposed CFFNN model.

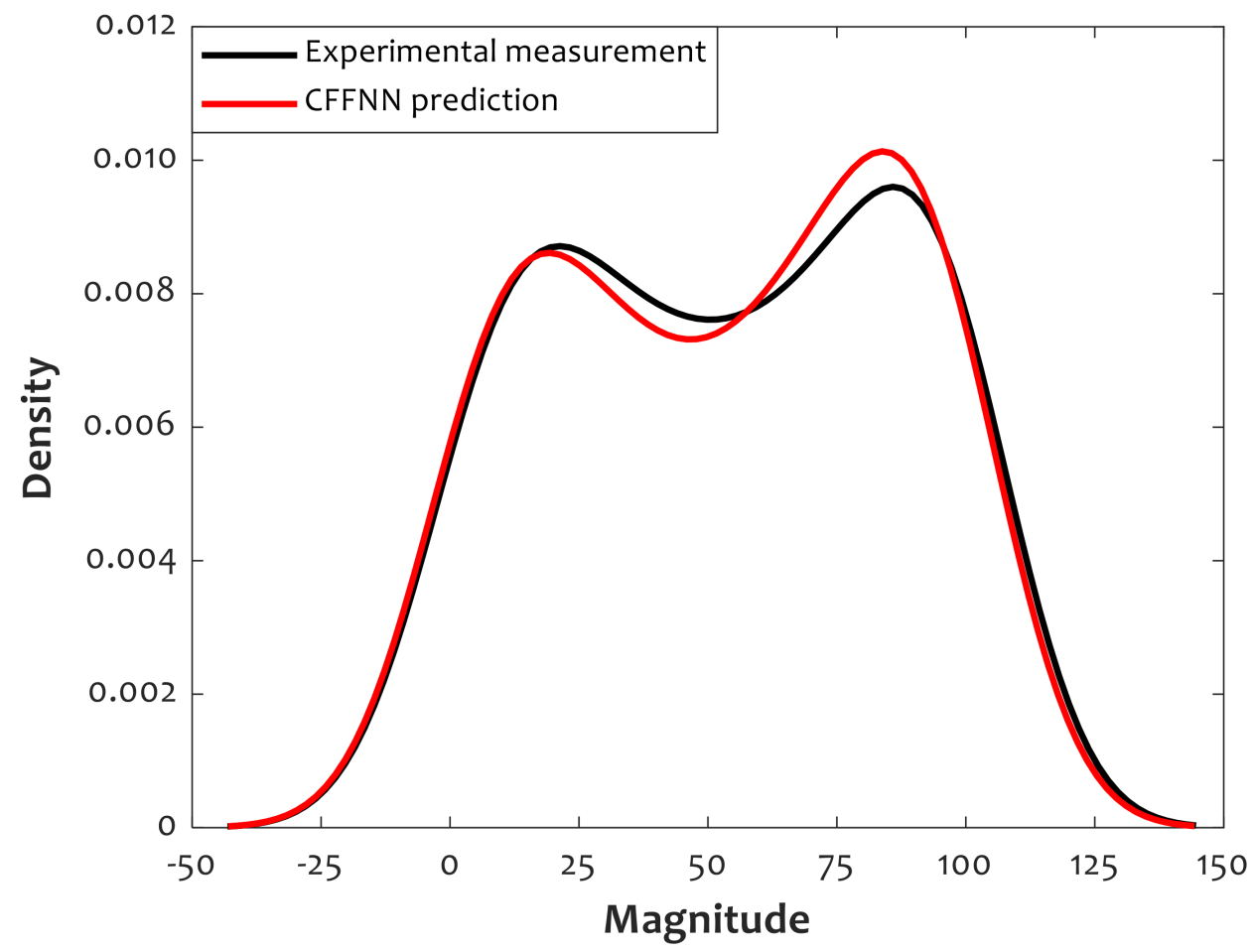

Figure 7. Kernel density estimation for actual measurements and CFFNN predictions.

\subsection{Checking the Validity of Experimental Data}

Since CFFNN has been constructed using experimental measurements of the relative crystallinity of PLLA/PGA composites, its reliability may be affected by potential outliers in the collected databank [51]. Therefore, it is a good idea to evaluate the level of poisoning of the experimental databank by such outliers [51]. The leverage is a practical statistical method for distinguishing valid and suspect measurements in a given database [51]. This method identifies valid/suspect data by plotting the standardized residual against the hat index (see Figure 8). The mathematical form of the standardized residual $(S R)$ is shown using Equation (7).

$$
S R=\left(\frac{R D}{S D}\right)_{k} k=1,2, \ldots, N
$$

A region bounded by $-3<$ standardized residual $<+3$ and Hat index $<$ warning leverage is valid, and all five other parts are suspect domains. Based on Equation (8), the numbers of influential factors $(I F)$ and experimental data $(N)$ are required to calculate the warning leverage $(W L)$. Since the current study utilizes three influential factors (i.e., crystallization time, crystallization temperature, and PGA dosage) to estimate relative crystallinity $(N=431), W L=0.0278$ (Figure 8 : vertical dashed green line) [39].

$$
W L=3 \times(I F+1) / N
$$




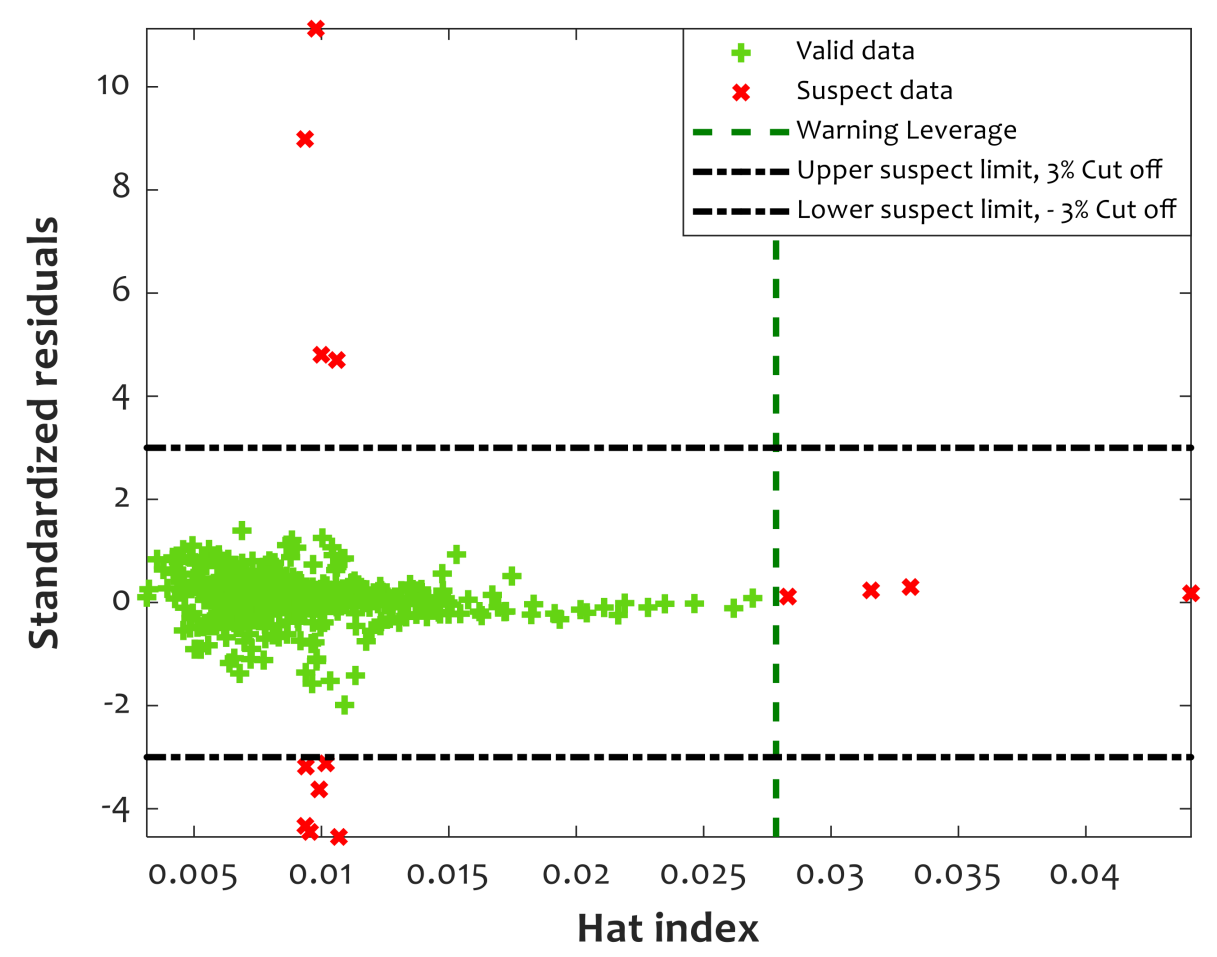

Figure 8. Applying leverage analysis to detect reliable as well as outlier information.

The outcomes of applying the leverage method on the PLLA/PGA crystallization database are depicted in Figure 8. It can be seen that 417 datasets are valid, and only 14 measurements may be outliers. Applying the leverage method to the experimental database demonstrates that more than $97 \%$ are valid measurements. Therefore, the validity of the experimental data is approved, and the engineered CFFNN method is ready to be used in real applications.

\subsection{Monitoring the Effect of Influential Features on Relative Crystallinity}

Figure 9 utilizes experimentally measured information as well as CFFNN prediction to investigate the effect of time and mass dosage of PGA fibers on the relative crystallinity of pure PLLA and its composites. An excellent compatibility level exists between actual and predicted crystallinity information. Experimental observations, as well as modeling results, show that the relative crystallinity of pure PLLA and PLLA/PGA gradually increases with increasing time. Furthermore, increasing the PGA mass dosage from $0 \%$ to $8 \%$ decreases the time needed to reach the maximum relative crystallinity of $100 \%$. It can be seen that pure PLLA experiences maximum crystallinity at $50 \mathrm{~min}$, while the PLLA/PGA composite reaches the maximum value after just $30 \mathrm{~min}$. It can be concluded that the addition of PGA fibers to the PLLA structure improves the crystallization rate. However, all composites reach maximum crystallinity in half the time that is required for pure PLLA.

The effect of PGA fiber dosage and crystallization time on the relative crystallinity of PLLA/PGA composites is shown in Figure 10. This figure shows that the required time for achieving full crystallization decreases by increasing the PGA content in the composite structure. The composite containing 8 weight percent of PGA fibers reaches maximum crystallinity faster than the other available PLLA/PGA composites. 


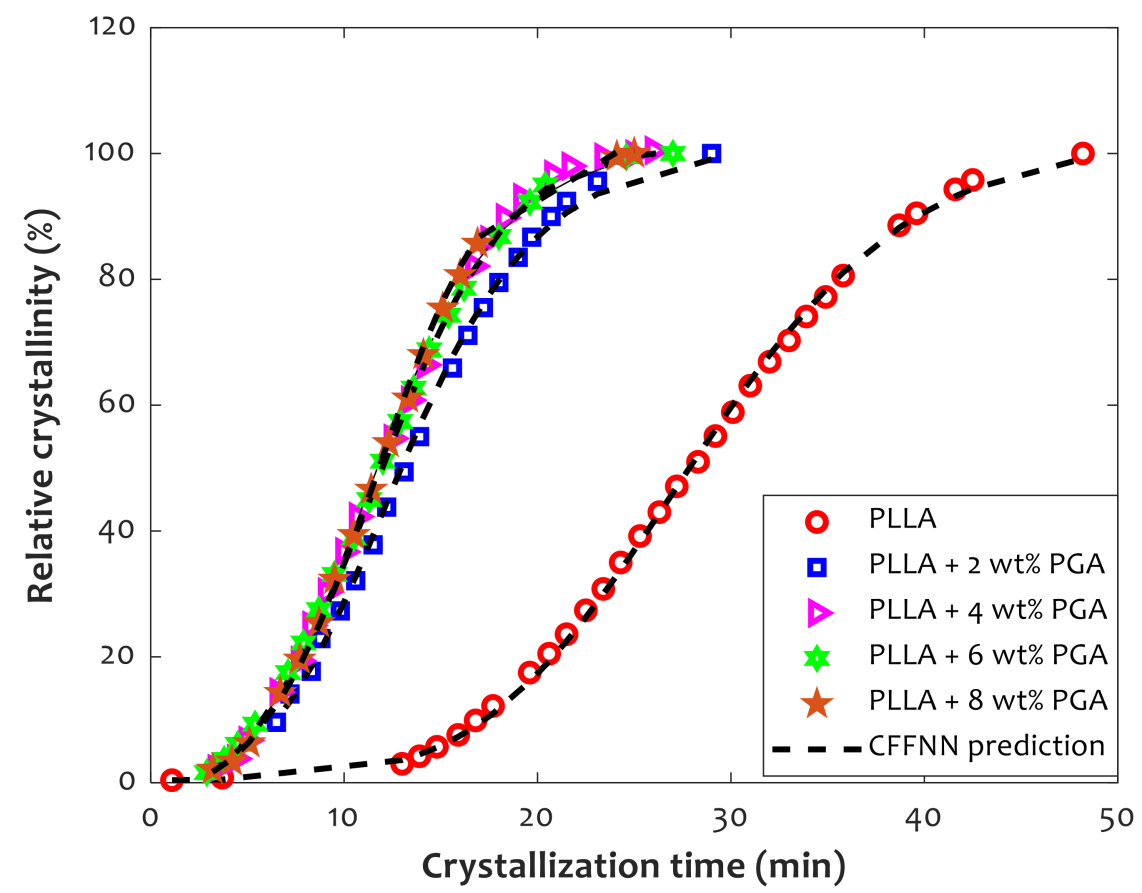

Figure 9. The effect of PGA dosage and crystallization time on rate of crystallization at $125^{\circ} \mathrm{C}$.

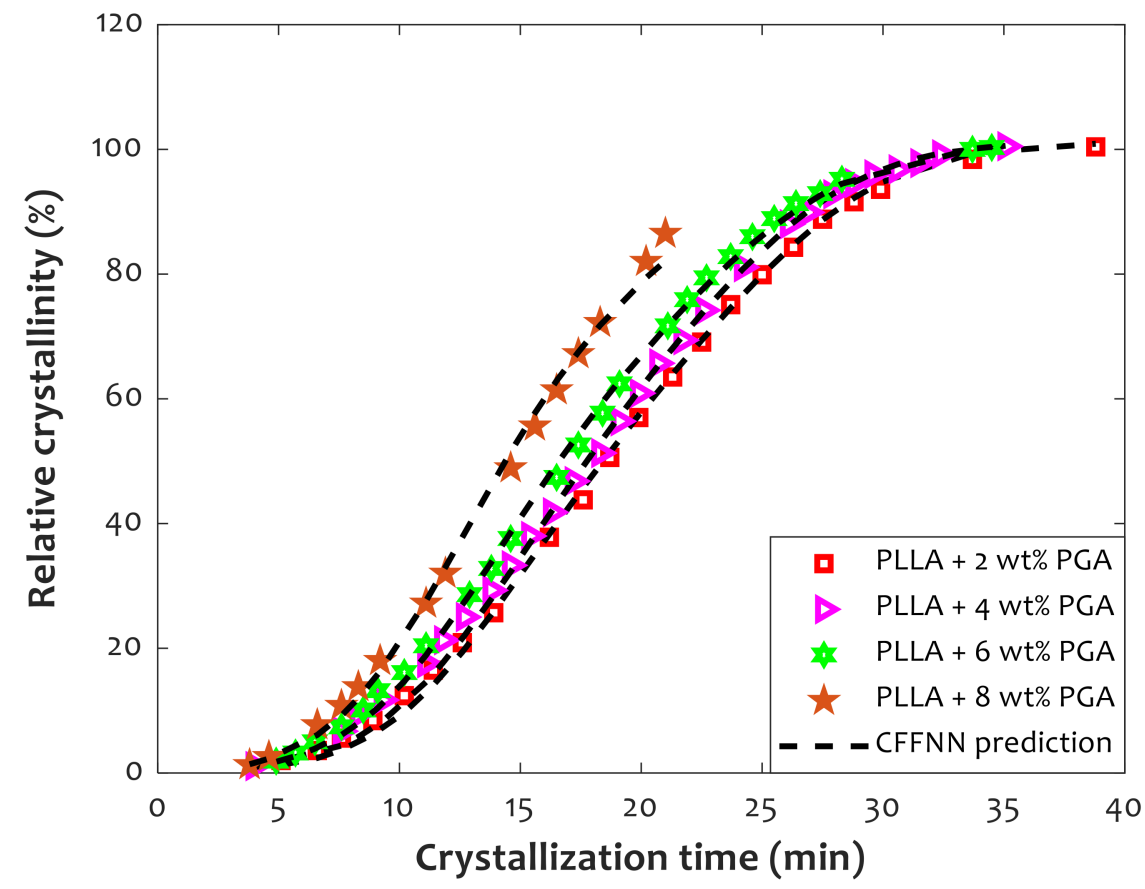

Figure 10. How PGA dosage affects relative crystallization of PLLA/PGA composites at $85^{\circ} \mathrm{C}$.

The effect of temperature on the relative crystallinity of PLLA-based composites containing $8 \mathrm{wt} \%$ of PGA fibers is presented in Figure 11. It can easily be seen that relative crystallinity shows a complex reaction to temperature change. Despite this complex behavior, CFFNN successfully predicted crystallinity variation and estimated all individual experimental samples. 


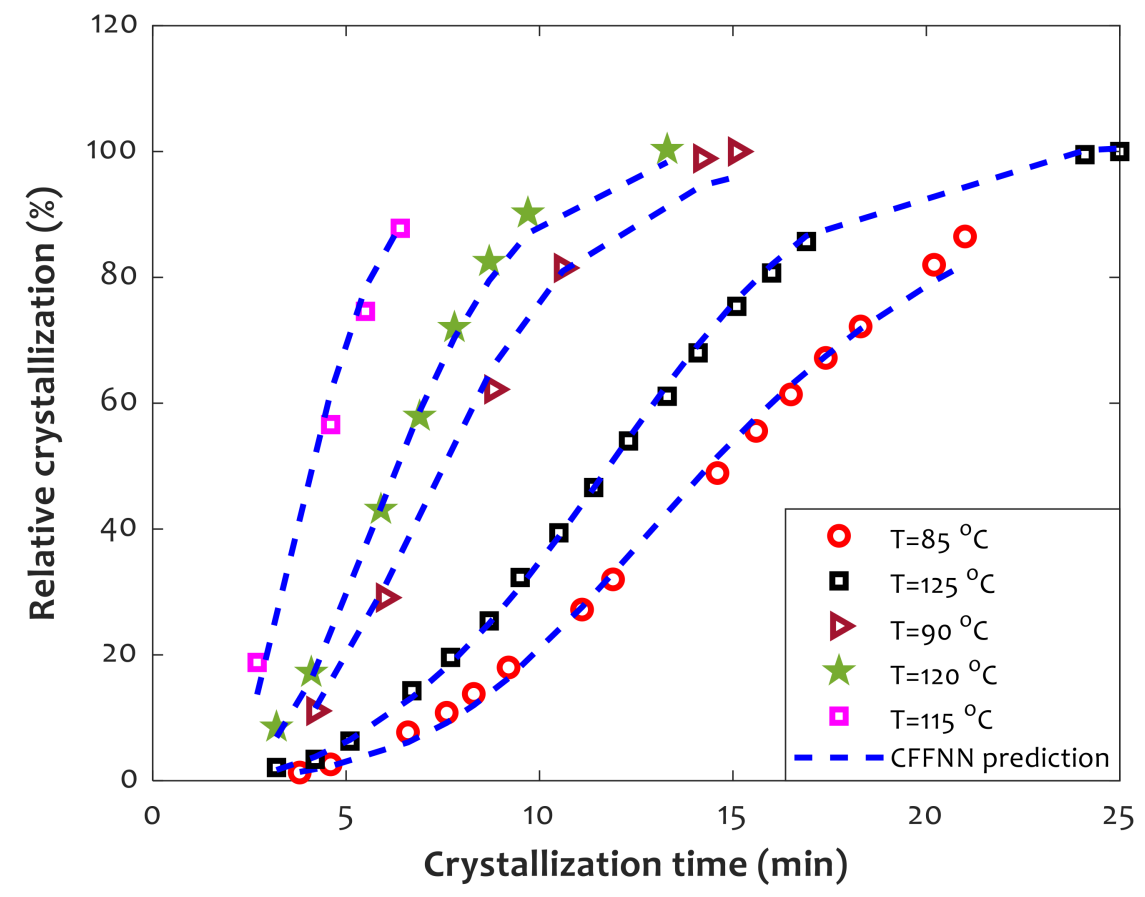

Figure 11. Isothermal relative crystallinity of the PLLA/PGA composite with $8 \mathrm{wt} \%$ of the fiber.

Relative crystallization from below the melting temperature to above glass temperature often shows a complex behavior [13]. This complex behavior is observed in long-chain polymers and also monomeric substances [13]. At the vicinity of melting temperature, the crystallization rate is very slow [13]. As the temperature further decreases, the crystallization rate gradually increases and finally reaches its maximum value [13]. At temperatures below this maximum condition, the overall crystallization rate is retarded once again [13].

\subsection{Transferability of the Proposed Model}

All empirical, semi-empirical, or intelligent methodologies extracted from historical data are only applicable for interpolation purposes on a considered system. Indeed, their extrapolation ability is so limited that they should be used with caution. Therefore, the deployed cascade feedforward neural network in this study can only be applied to estimate the relative crystallinity of biodegradable polylactic acid and polyglycolide polymer composites covering the reported values in Table 1. There is no guarantee of accurately estimating the relative crystallinity of other polymer composites using the constructed CFFNN machine.

\section{Conclusions}

This study used six different machine learning categories to correlate the relative crystallinity of pure PLLA and PLLA/PGA composites to crystallization time, crystallization temperature, and PGA dosage in composites. So many intelligent models have been constructed, and their accuracy has been compared to choose the best one for the given purpose. The ranking study using four accuracy indices confirmed that the cascade feedforward neural network has the highest level of agreement with the 431 experimentally measured datasets. This model predicted the available databank with an extraordinary correlation coefficient $\left(R^{2}\right)$ of 0.999008 , root mean squared errors of $4.67 \%$, and average absolute percentage difference of $8.84 \%$. Reliability checking confirmed that $97 \%$ of the experimental information is valid. The results also showed that relative crystallinity directly relates to crystallization time and PGA dosage in the composites, and it has a weak indirect relationship with crystallization temperature. Indeed, relative crystallinity increases by increasing time and PGA dosage in the composites. On the other hand, variation of relative 
crystallinity based on temperature is too complex to suggest a general route for its behavior. The literature has also observed such complex behavior for both long-chain polymers and monomeric substances.

Supplementary Materials: The following supporting information can be downloaded at: https: / / www.mdpi.com/article/10.3390/polym14030527/s1, Data and MATLAB source codes.

Author Contributions: Conceptualization, J.W., M.A.A., A.K. and B.V.; methodology, J.W., M.A.A., A.K., M.E.H.C. and S.A.U.Z.; software, T.R.; formal analysis, A.K.; investigation, J.W., M.A.A., A.K., S.A.U.Z., M.E.H.C. and B.V.; writing — original draft preparation, J.W.; writing—review and editing, M.E.H.C. and T.R.; All authors have read and agreed to the published version of the manuscript.

Funding: This research received no external funding.

Institutional Review Board Statement: Not applicable.

Informed Consent Statement: Not applicable.

Data Availability Statement: The data and MATLAB source codes have been provided as supplementary files.

Acknowledgments: The Science and Technology Plan Projects of Yulin City (2019-85-1).

Conflicts of Interest: The authors declare no conflict of interest.

\section{References}

1. Puppi, D.; Chiellini, F. Biodegradable Polymers for Biomedical Additive Manufacturing. Appl. Mater. Today 2020, $20,100700$. [CrossRef]

2. Iqbal, N.; Khan, A.S.; Asif, A.; Yar, M.; Haycock, J.W.; Rehman, I.U. Recent concepts in biodegradable polymers for tissue engineering paradigms: A critical review. Int. Mater. Rev. 2019, 64, 91-126. [CrossRef]

3. Raza, F.; Zafar, H.; Zhu, Y.; Ren, Y.; Ullah, A.; Khan, A.U.; He, X.; Han, H.; Aquib; Boakye-Yiadom, K.O.; et al. A Review on Recent Advances in Stabilizing Peptides/Proteins upon Fabrication in Hydrogels from Biodegradable Polymers. Pharmaceutics 2018, 10, 16. [CrossRef] [PubMed]

4. Lai, W.-F.; Huang, E.; Lui, K.-H. Alginate-based complex fibers with the Janus morphology for controlled release of co-delivered drugs. Asian J. Pharm. Sci. 2021, 16, 77-85. [CrossRef]

5. Lai, W.-F.; Wong, W.-T. Use of graphene-based materials as carriers of bioactive agents. Asian J. Pharm. Sci. 2020, 16, 577-588. [CrossRef]

6. Bahador, F.; Foroutan, R.; Esmaeili, H.; Ramavandi, B. Enhancement of the chromium removal behavior of Moringa oleifera activated carbon by chitosan and iron oxide nanoparticles from water. Carbohydr. Polym. 2021, 251, 117085. [CrossRef]

7. Nemati, F.; Jafari, D.; Esmaeili, H. Highly efficient removal of toxic ions by the activated carbon derived from Citrus limon tree leaves. Carbon Lett. 2021, 31, 509-521. [CrossRef]

8. Shi, C.; Wu, Z.; Yang, F.; Tang, Y. Janus particles with pH switchable properties for high-efficiency adsorption of PPCPs in water. Solid State Sci. 2021, 119, 106702. [CrossRef]

9. Liu, Y.; Zhang, Q.; Yuan, H.; Luo, K.; Li, J.; Hu, W.; Pan, Z.; Xu, M.; Xu, S.; Levchenko, I.; et al. Comparative study of photocatalysis and gas sensing of $\mathrm{ZnO} / \mathrm{Ag}$ nanocomposites synthesized by one- and two-step polymer-network gel processes. J. Alloys Compd. 2021, 868, 158723. [CrossRef]

10. Tsuji, H.; Takai, H.; Fukuda, N.; Takikawa, H. Non-Isothermal Crystallization Behavior of Poly(L-lactic acid) in the Presence of Various Additives. Macromol. Mater. Eng. 2006, 291, 325-335. [CrossRef]

11. Dobreva, T.; Pereña, J.; Pérez, E.; Benavente, R.; García, M. Crystallization behavior of poly(L -lactic acid)-based ecocomposites prepared with kenaf fiber and rice straw. Polym. Compos. 2010, 31, 974-984. [CrossRef]

12. Chen, H.; Ma, C.; Bai, W.; Chen, N.; Xiong, C. Isothermal Crystallization and Melting Behavior of Composites Composed of Poly(L-lactic Acid) and Poly(glycolic Acid) Fibers. J. Macromol. Sci. Part B 2014, 53, 1715-1725. [CrossRef]

13. Mandelkern, L. Crystallization of Polymers: Volume 2, Kinetics and Mechanisms; Cambridge University Press: Cambridge, UK, 2004.

14. Piorkowska, E.; Rutledge, G.C. Handbook of Polymer Crystallization; John Wiley \& Sons: Amsterdam, The Netherlands, 2013.

15. Liu, L.; Xu, Y.; Pan, Y.; Xu, M.; Di, Y.; Li, B. Facile synthesis of an efficient phosphonamide flame retardant for simultaneous enhancement of fire safety and crystallization rate of poly (lactic acid). Chem. Eng. J. 2021, 421, 127761. [CrossRef]

16. Suryanegara, L.; Nakagaito, A.N.; Yano, H. The effect of crystallization of PLA on the thermal and mechanical properties of microfibrillated cellulose-reinforced PLA composites. Compos. Sci. Technol. 2009, 69, 1187-1192. [CrossRef]

17. Ghanbari, S.; Vaferi, B. Prediction of degree of crystallinity for the LTA zeolite using artificial neural networks. Mater. Sci. 2017, 35, 486-495. [CrossRef]

18. Crawford, C.B.; Quinn, B. Physiochemical properties and degradation. In Microplastic Pollutants; Elsevier: Amsterdam, The Netherlands, 2017; pp. 57-100. 
19. Balani, K.; Verma, V.; Agarwal, A.; Narayan, R. Physical, Thermal, and Mechanical Properties of Polymers. Biosurfaces 2015, 329-344. [CrossRef]

20. Murthy, N.S. Experimental Techniques for understanding polymer crystallization. In Crystallization in Multiphase Polymer Systems; Elsevier: Amsterdam, The Netherlands, 2018; pp. 49-72.

21. Ming, Y.; Zhou, Z.; Hao, T.; Nie, Y. Molecular simulation of polymer crystallization under chain and space confinement. Phys. Chem. Chem. Phys. 2021, 23, 17382-17391. [CrossRef]

22. Rahman, T.; Al-Ishaq, F.A.; Al-Mohannadi, F.S.; Mubarak, R.S.; Al-Hitmi, M.H.; Islam, K.R.; Khandakar, A.; Hssain, A.A.; Al-Madeed, S.; Zughaier, S.M.; et al. Mortality Prediction Utilizing Blood Biomarkers to Predict the Severity of COVID-19 Using Machine Learning Technique. Diagnostics 2021, 11, 1582. [CrossRef]

23. Rahman, T.; Khandakar, A.; Hoque, E.; Ibtehaz, N.; Bin Kashem, S.; Masud, R.; Shampa, L.; Hasan, M.M.; Islam, M.T.; Al-Maadeed, S.; et al. Development and Validation of an Early Scoring System for Prediction of Disease Severity in COVID-19 Using Complete Blood Count Parameters. IEEE Access 2021, 9, 120422-120441. [CrossRef]

24. Chowdhury, M.E.H.; Rahman, T.; Khandakar, A.; Al-Madeed, S.; Zughaier, S.M.; Doi, S.A.R.; Hassen, H.; Islam, M.T. An Early Warning Tool for Predicting Mortality Risk of COVID-19 Patients Using Machine Learning. Cogn. Comput. 2021, 1-16. [CrossRef]

25. Kumar, S.; Ignacz, G.; Szekely, G. Synthesis of covalent organic frameworks using sustainable solvents and machine learning. Green Chem. 2021, 23, 8932-8939. [CrossRef]

26. Hardian, R.; Liang, Z.; Zhang, X.; Szekely, G. Artificial intelligence: The silver bullet for sustainable materials development. Green Chem. 2020, 22, 7521-7528. [CrossRef]

27. He, S.; Guo, F.; Zou, Q.; Ding, H. MRMD2.0: A Python Tool for Machine Learning with Feature Ranking and Reduction. Curr. Bioinform. 2021, 15, 1213-1221. [CrossRef]

28. Al Omar, A.; Jamil, A.K.; Khandakar, A.; Uzzal, A.R.; Bosri, R.; Mansoor, N.; Rahman, M.S. A Transparent and Privacy-Preserving Healthcare Platform With Novel Smart Contract for Smart Cities. IEEE Access 2021, 9, 90738-90749. [CrossRef]

29. Khandakar, A.; Chowdhury, M.E.H.; Gonzales, A., Jr.; Pedro, S.; Touati, F.; Emadi, N.A.; Ayari, M.A. Case Study to Analyze the Impact of Multi-Course Project-Based Learning Approach on Education for Sustainable Development. Sustainability 2020, 12, 480. [CrossRef]

30. Rastogi, S.; Choudhary, S. Face Recognition by Using Neural Network. Acta Inform. Malays. 2019, 3, 7-9. [CrossRef]

31. Gholami, E.; Vaferi, B.; Ariana, M.A. Prediction of viscosity of several alumina-based nanofluids using various artificial intelligence paradigms-Comparison with experimental data and empirical correlations. Powder Technol. 2018, 323, 495-506. [CrossRef]

32. Esmaeili-Faraj, S.H.; Vaferi, B.; Bolhasani, A.; Karamian, S.; Hosseini, S.; Rashedi, R. Design of a Neuro-Based Computing Paradigm for Simulation of Industrial Olefin Plants. Chem. Eng. Technol. 2021, 44, 1382-1389. [CrossRef]

33. Mahmoodi, F.; Darvishi, P.; Vaferi, B. Prediction of coefficients of the Langmuir adsorption isotherm using various artificial intelligence (AI) techniques. J. Iran. Chem. Soc. 2018, 15, 2747-2757. [CrossRef]

34. Moghimihanjani, M.; Vaferi, B. A Combined Wavelet Transform and Recurrent Neural Networks Scheme for Identification of Hydrocarbon Reservoir Systems From Well Testing Signals. J. Energy Resour. Technol. 2021, 143, 013001. [CrossRef]

35. Mousavi, N.S.; Vaferi, B.; Romero-Martínez, A. Prediction of Surface Tension of Various Aqueous Amine Solutions Using the UNIFAC Model and Artificial Neural Networks. Ind. Eng. Chem. Res. 2021, 60, 10354-10364. [CrossRef]

36. Vaferi, B.; Eslamloueyan, R.; Ayatollahi, S. Application of Recurrent Networks to Classification of Oil Reservoir Models in Well-testing Analysis. Energy Sour. Part A Recover. Util. Environ. Eff. 2014, 37, 174-180. [CrossRef]

37. Cybenko, G. Approximation by superpositions of a sigmoidal function. Math. Control. Signals, Syst. 1989, 2, 303-314. [CrossRef]

38. Karimi, M.; Aminzadehsarikhanbeglou, E.; Vaferi, B. Robust intelligent topology for estimation of heat capacity of biochar pyrolysis residues. Measurement 2021, 183, 109857. [CrossRef]

39. Moosavi, S.R.; Vaferi, B.; Wood, D.A. Auto-characterization of naturally fractured reservoirs drilled by horizontal well using multi-output least squares support vector regression. Arab. J. Geosci. 2021, 14, 545. [CrossRef]

40. Suykens, J.A.K.; Van Gestel, T.; De Brabanter, J.; De Moor, B.; Vandewalle, J. Least Squares Support Vector Machines; World Scientific Publishing: Singapore City, Singapore, 2002.

41. Keshtkar, Z.; Tamjidi, S.; Vaferi, B. Intensifying nickel (II) uptake from wastewater using the synthesized $\gamma$-alumina: An experimental investigation of the effect of nano-adsorbent properties and operating conditions. Environ. Technol. Innov. 2021, 22, 101439. [CrossRef]

42. Daryayehsalameh, B.; Nabavi, M.; Vaferi, B. Modeling of $\mathrm{CO}_{2}$ capture ability of [Bmim] [BF4] ionic liquid using connectionist smart paradigms. Environ. Technol. Innov. 2021, 22, 101484. [CrossRef]

43. Khandakar, A.; Chowdhury, M.E.; Reaz, M.B.I.; Ali, S.H.M.; Hasan, A.; Kiranyaz, S.; Rahman, T.; Alfkey, R.; Bakar, A.A.A.; Malik, R.A. A machine learning model for early detection of diabetic foot using thermogram images. Comput. Biol. Med. 2021, 137, 104838. [CrossRef]

44. Lu, S.X.; Zhou, Q.Z.; Fan, R. Analysis of the Relevancy between Energy Consumption and Environmental Pollution Based on Grey Theory. Adv. Mater. Res. 2012, 616-618, 1404-1408. [CrossRef]

45. Jiang, Y.; Zhang, G.; Wang, J.; Vaferi, B. Hydrogen solubility in aromatic/cyclic compounds: Prediction by different machine learning techniques. Int. J. Hydrogen Energy 2021, 46, 23591-23602. [CrossRef]

46. Xie, J.; Liu, X.; Lao, X.; Vaferi, B. Hydrogen solubility in furfural and furfuryl bio-alcohol: Comparison between the reliability of intelligent and thermodynamic models. Int. J. Hydrogen Energy 2021, 46, 36056-36068. [CrossRef] 
47. Vaferi, B.; Lashkarbolooki, M.; Esmaeili, H.; Shariati, A. Toward artificial intelligence-based modeling of vapor liquid equilibria of carbon dioxide and refrigerant binary systems. J. Serb. Chem. Soc. 2018, 83, 199-211. [CrossRef]

48. Karimi, M.; Vaferi, B.; Hosseini, S.; Olazar, M.; Rashidi, S. Smart computing approach for design and scale-up of conical spouted beds with open-sided draft tubes. Particuology 2021, 55, 179-190. [CrossRef]

49. Ghanbari, S.; Vaferi, B. Experimental and theoretical investigation of water removal from DMAZ liquid fuel by an adsorption process. Acta Astronaut. 2015, 112, 19-28. [CrossRef]

50. Wood, D.A.; Choubineh, A.; Vaferi, B. Transparent Open-Box Learning Network Provides Auditable Predictions: Pool Boiling Heat Transfer Coefficient for Alumina-Water-Based Nanofluids. J. Therm. Anal. Calorim. 2019, 136, 1395-1414. [CrossRef]

51. Zhou, Z.; Davoudi, E.; Vaferi, B. Monitoring the effect of surface functionalization on the $\mathrm{CO}_{2}$ capture by graphene oxide/methyl diethanolamine nanofluids. J. Environ. Chem. Eng. 2021, 9, 106202. [CrossRef]

52. Vaferi, B.; Eslamloueyan, R.; Ayatollahi, S. Automatic recognition of oil reservoir models from well testing data by using multi-layer perceptron networks. J. Pet. Sci. Eng. 2011, 77, 254-262. [CrossRef]

53. Atashi, A.; Nazeri, N.; Abbasi, E.; Dorri, S.; Alijani-Z, M. Breast Cancer Risk Assessment Using adaptive neuro-fuzzy inference system (ANFIS) and Subtractive Clustering Algorithm. Multidiscip. Cancer Investig. 2017, 1, 20-26. [CrossRef]

54. Abdulshahed, A.M.; Longstaff, A.P.; Fletcher, S.; Myers, A. Thermal error modelling of machine tools based on ANFIS with fuzzy c-means clustering using a thermal imaging camera. Appl. Math. Model. 2015, 39, 1837-1852. [CrossRef]

55. Hosseini, S.; Vaferi, B. Determination of Methanol Loss Due to Vaporization in Gas Hydrate Inhibition Process Using Intelligent Connectionist Paradigms. Arab. J. Sci. Eng. 2021, 1-9. [CrossRef]

56. Lacour, C.; Massart, P.; Rivoirard, V. Estimator Selection: A New Method with Applications to Kernel Density Estimation. Sankhya A 2017, 79, 298-335. [CrossRef] 